\title{
A Comparison of The Analgesic Effects of Fentanyl And Butorphanol In African Clawed Frogs (Xenopus laevis) Under Tricaine Methanesulfonate (MS222) Anaesthesia
}

Sophie Strobel ${ }^{1}$, Alexa Hagedorn ${ }^{3}$, Sibylle Ott ${ }^{3}$, Hermann Kempf, Birgit Waschulzik ${ }^{2}$, Michael Gröger ${ }^{4}$, Sandra Kress $^{4}$, Peter Radermacher ${ }^{4}$, Heidrun Potschka ${ }^{5}$ and Christine M. Baumgartner ${ }^{1^{*}}$

${ }^{1}$ Centre of Preclinical Research, Klinikum rechts der Isar,Technical University of Munich (81675 Munich, Germany)

${ }^{2}$ Institute for Medical Statistics and Epidemiology, Technical University of Munich (81675 Munich, Germany)

${ }^{3}$ Tierforschungszentrum, University of Ulm (89081 Ulm, Germany)

${ }^{4}$ the Institut für Anästhesiologische Pathophysiologie und Verfahrensentwicklung University of Ulm (89081 Ulm, Germany).

${ }^{5}$ the Institute for Pharmacology, Toxicology and Pharmaceutics Ludwig-Maximilians-University of Munich (80539 Munich, Germany).

Received: June 15 2018; Accepted: July 16 2018; Published: July 262018

*Corresponding author: Christine M. Baumgartner, Centre Of Preclinical Research, Klinikum r. d. Isar, Technical University of Munich,Ismaninger Str. 22, D-81675 Munich, Germany. Tel:+49 894140 4472; E-mail: Christine.Baumgartner@tum.de

\begin{abstract}
In this two-part study, the potency of two analgesics on nociception was assessed in African Clawed Frogs (ACFs). First, three different Pain Stimuli (PSs) were evaluated in the frogs during Tricaine Methanesulfonate (MS222) anaesthesia. Using the most effective PS from the preliminary study, the analgesic effects of three different doses of fentanyl and butorphanol were examined in frogs under MS222 anaesthesia.

Comparing the three different PSs (5\% acetic acid onto skin, toe pinch by a clamp and pull on the ovaries), continuous Blood Pressure (BP) and Heart Rate (HR) recordings of the frogs indicated a sharp and reproducible increase in both parameters in response to acetic acid. That result clearly indicated an increased nociception during MS222 anaesthesia. Therefore, MS222 alone does not provide sufficient analgesia for painful interventions in ACFs. From all tested analgesic groups only $5 \mathrm{mg} / \mathrm{kg}$ butorphanol showed a short lasting decreased $\mathrm{BP}$ and HR response. In contrast, neither lower dosed butorphanol nor fentanyl in general reduced BP and HR response to a PS, only producing considerable side effects on the haemodynamic system.
\end{abstract}

These findings argue against using fentanyl as an analgesic in ACFs. Butorphanol significantly reduced the nociception in the high dose group. However, considering its limited duration of action and potential adverse effects, further analgesics (e.g., ketamine and metamizole) should be evaluated to improve intraoperative analgesia when using MS222 anaesthesia in ACFs.

Key words: Analgesic Effects; Fentanyl; Butorphanol; African Clawed Frogs; Tricaine Methanesulfonate (MS222);

\section{Introduction}

Xenopus laevis, the African Clawed Frog (ACF), is a widely used laboratory animal and the most frequently used amphibian species in biomedical research [1-3]. Xenopus has retained its status as a widely used animal model with various uses in research. In addition to its ethological aspects, various qualities have made Xenopus laevis popular, e.g., its robustness, its simple husbandry and the possibility of working with three different developmental stages (oocytes/larvae/adults) [4 \& 5]. Of those three, oocytes are the most commonly used developmental stage. They are harvested via laparotomy and the excision of a small portion of the ovarian mass, which is the most common surgery for Xenopus and is repeatedly performed in female animals [6 \& 7]. Surgeries are usually conducted under anaesthesia with MS222 with no additional analgesics Currently, MS222 is the agent of choice for inducing general anaesthesia in fish and amphibians [8-11]. As an isomer of benzocaine, it is watersoluble and has a short induction time, a tolerance phase that can be variously prolonged and a short recovery phase [12]. With few exceptions and when given via immersion, MS222 is described as being a safe anaesthetic with a low impact on heart rate and oxygen saturation [13-15 \& 19]. In pain research, amphibians have gradually established a small but adequate status as animal models, even though their ability for nociception and to pain perception, has been controversially discussed in the past [20-22]. In 1969, Kaplan declared that pain perception is not particularly developed in all poikilotherms due to their low phylogenetic position and underdeveloped brain [23]. However, according to Guénette et al., it is now commonly accepted that amphibians possess neuroanatomical pathways conductive of a complete nociceptive experience. In general, nociception is defined as the transmission of pain from a peripheral receptor, usually an unmyelinated nerve ending, to the central nervous system and brain processing is the final process where pain perception occurs in conscious animals [24]. According to several studies frogs have nociceptors in superficial and deep layers of the skin transducing mechanical and chemical noxious stimuli [25-28]. And furthermore frogs also have both myelinated and unmyelinated afferent fibres that compose the peripheral sensory nervous system [29]. These fibres, identified as large diameter A $\delta$ fibres and C fibres are similar to those found in mammals [24 
\& 30]. Pathways via the spinothalamic or trigeminal tract have been relatively underexplored, but studies have shown these are comparable with mammals [30 \& 31]. These findings indicate that frogs perceive nociception during anaesthesia and therefore whenever painful surgical procedures are performed, a proper anaesthetic regime including sufficient analgesia must be chosen.

Commonly, general anaesthesia in animals including surgical tolerance is defined by inducing hypnosis (unconsciousness), muscle relaxation and analgesia. To cover all three aspects, combination of drugs is necessary in mammals. This allows lower doses of each drug, therefore less side effects and increased safety respectively. In the sense of a balanced anaesthetic regime it is therefore necessary based on the duration of the experiment and the painful stimuli to combine anaesthetics which induce hypnosis and muscle relaxation with analgesics to ensure a sufficient depth of anaesthesia and to ensure a highly controllable anaesthetic management [32]

Currently, very little literature can be found that discusses intraoperative pain management in the belief that MS222, as an ideal anaesthetic, guarantees hypnosis, muscle relaxation and analgesia [14, 18 \& 33]. Therefore, the aim of this study was to clarify whether different Pain Stimuli (PSs) lead to nociception during anaesthesia with MS222. According to Dincklage, the Nociceptive Flexion Reflex Threshold best predicts movement and heart rate responses to noxious stimuli under general anaesthesia [34]. However, as this measurement system is not validated for poikilothermic animals, we used in accordance with Richter and Arras et al., the changes of Blood Pressure (BP) and Heart Rate (HR) response as an indicator for nociception [35 \& 36]. In the first part of the study, three different PSs were evaluated to identify the most sensitive and reproducible stimulus for nociception under MS222 anaesthesia. In the second part of the study, two opioids, fentanyl and butorphanol were evaluated at three different doses using the most reproducible nociceptive stimulus to investigate their analgesic potency under MS222.

\section{Animals, Materials and Methods}

\section{Animals and Husbandry}

In this explorative, not blinded study, 42 ( $\mathrm{n}=6$ in 7 groups; 1 preliminary and 6 analgesic testing groups) non breeding female ACFs with a mean body weight of $122.9 \pm 17.4 \mathrm{~g}$ (expressed as mean \pm SD) were used.

The frogs were obtained from an experimental breeding colony and were group-housed in $300 \mathrm{~L}$ aquariums, with a maximum number of 25 animals per group [a \& b]. The aquarium water was carbon-filtrated, dechlorinated tap water at a temperature of $18^{\circ} \mathrm{C} \pm 2{ }^{\circ} \mathrm{C}$ and a room temperature of $23^{\circ} \mathrm{C}$. The maintained $\mathrm{pH}$ value of the water was $8.2 \pm 2$. The water quality of the aquariums was monitored monthly by bacteriological analysis and every second month by measurement of nitrate $(5-10 \mathrm{mg} / \mathrm{L})$ and nitrite $(0.025-0.1 \mathrm{mg} / \mathrm{L})$. Every week, approximately one-third of the water was replaced.

A cycle of $14 \mathrm{~h}$ of light followed by $10 \mathrm{~h}$ of dark was maintained.
The animals were fed an alternating commercial pelleted diet and fresh beef heart twice a week [c]. Each aquarium offered two half pipes as enrichment items. Prior to anaesthesia, the animals were starved for at least $24 \mathrm{~h}$.

The study was approved by the governmental institution of Baden-Württemberg, Regierungspräsidium Tübingen (case number: 35/9185.81-3) and performed in accordance with the German Animal Welfare Act.

\section{Anaesthesia}

On the day of the experiment, the frogs were caught from the aquarium and placed in a non-transparent $10 \mathrm{~L}$ bucket filled with 2L dechlorinated, carbon-filtrated water. For transportation, the bucket was covered and sudden movements avoided.

The experiments were conducted from 8 am to 4 pm under standardised room temperature conditions with an average room temperature of $23^{\circ} \mathrm{C}$. Prior to the surgery, anaesthesia was induced by immersion of the frog in $1 \mathrm{~g} / \mathrm{L}$ MS222 (tricaine methanesulfonate) in a covered dark container for 30 minutes [d]. As the pure solution of MS222 has a pH of 1-2, it was buffered to a $\mathrm{pH}$ of 7.0 by adding sodium bicarbonate [e]. Once the corneal, swallowing, wiping and righting reflexes were no longer evident, the frogs were weighed and then placed at a $10^{\circ}$ incline. Anaesthesia was maintained via continuous flushing of $0.5 \mathrm{~g} / \mathrm{L}$ MS222 at an infusion rate of $1 \mathrm{~mL} / 30 \mathrm{sec}$ [f]. The tube of the syringe pump was placed on top of the incline operation field and rinsed the backside of the animal [f]. To keep their skin moist, the animals were covered with a soft wet gauze pad and rinsed with frog ringer $(0.65 \%$ saline solution $)$ at least 3 times per minute [g\& h].

\section{Experimental protocol}

As experiments were final, operations were not conducted under sterile surgical conditions. Each frog was placed on its back, and a paramedian incision of $3 \mathrm{~cm}$ was made in the cranial third of the body to open the coelom. A small silicon tube was inserted into the superficial abdominal vein to enable the intravenous application of the placebo or the two different opioids [i]. For HR and systolic BP measurement, a micro-tip catheter was placed in the heart ventricle. To gain access to the heart, it was necessary to remove the main part of the chest cartilage. The ventricle was punctured by a 20G cannula and the micro-tip catheter was quickly inserted and fixed by a prepared purse-string suture $[\mathrm{j}$, $\mathrm{k} \& \mathrm{l}]$. The catheter was connected to a recording device that monitored the intraventricular BP and HR every two seconds [m]. After the surgical procedures, a 10-minute period of rest was taken, during which the skin was constantly kept moist by rinses with the frog ringer.

In the preliminary study, three different PSs according to a randomized study plan were applied to six animals:

1) An Acetic acid Test (AAT): $5 \%$ acetic acid was dropped onto the skin of the thigh and washed off with $20 \mathrm{~mL}$ of frog ringer after $5 \mathrm{sec}[\mathrm{n}]$.

2) A pinch by a bulldog clamp in the dactyls of the forelimbs for 
$5 \mathrm{sec}$.

3) A pull on the ovaries by forceps for $5 \mathrm{sec}$. After the first PS, the placebo $(500 \mu \mathrm{L}$ frog ringer) was given intravenously. Then, each PS was given twice at intervals of 10 minutes in a randomized sequence.

In the second part of the study, after identification of the most sensitive and reproducible PS, additional fentanyl and butorphanol were examined in three different doses each in accordance with literature [o \& p] [37-42]. The chosen doses for fentanyl were $0.05,0.25$ and $0.5 \mathrm{mg} / \mathrm{kg}$, and for butorphanol 0.05 , 1.0 and $5.0 \mathrm{mg} / \mathrm{kg}$, respectively. Six randomly allocated animals were investigated per dosage group.

Painful test stimuli using the formerly identified PS were executed before application of the analgesics (PS 1) and thereafter in 10 minutes intervals (until 50 minutes after application, PS 2-5). BP and HR were continuously observed before and after applying the PS. The data one minute prior to a PS were taken as baseline reference value. During the minute directly after the PS, the peak value of both BP and HR were highlighted. The difference between maximum and baseline, delta $(\Delta)$, showed the increase in BP and HR.

At the end of the experimental protocol, $1 \mathrm{~mL}$ of heart blood was taken directly before euthanasation of the frog by an intracardiac overdose of thiopental $(100 \mathrm{mg} / \mathrm{kg})[\mathrm{q}][9,15$ \& 43]. Drug serum level was measured from the blood sample afterwards.

\section{Statistical evaluation}

The statistical analysis was performed using the software package SPSS [r]. Descriptive statistics regarding the distribution of the group differences in systolic BP and HR are given by the mean and standard deviation as well as by the percentage change. As the study was explorative, no adjustment for multiple comparisons was necessary. For pair wise group comparisons, either paired sample t-tests (comparison of the five different PS) or independent paired t-tests were conducted in an explorative manner and at a significance level of 0.05 (two-sided). To compare the three different serum levels of fentanyl and butorphanol, a one-way analysis of variance (ANOVA) and (in case of statistical significance) post hoc tests (Tuckey-HSD) were performed (significance level of 0.05 ; two-sided). Illustrations are given by dynamic plots (with mean and error bars) or box plots.

\section{Results}

\section{Preliminary study}

Results from five animals were evaluated. One frog was excluded due to cardiovascular depression while baseline data monitoring. Overall, each PS provoked an increase in the HR and systolic BP of the anaesthetised Xenopus (Figure 1). The delta of the BP was $1.65 \pm 1.82 \mathrm{mmHg}$ (mean \pm SD) after pinches by the bulldog clamp, which corresponds to an increase of $6.0 \%$. The delta of the HR was $4.10 \pm 3.54 \mathrm{bpm}$, which is an increase of $10.5 \%$.

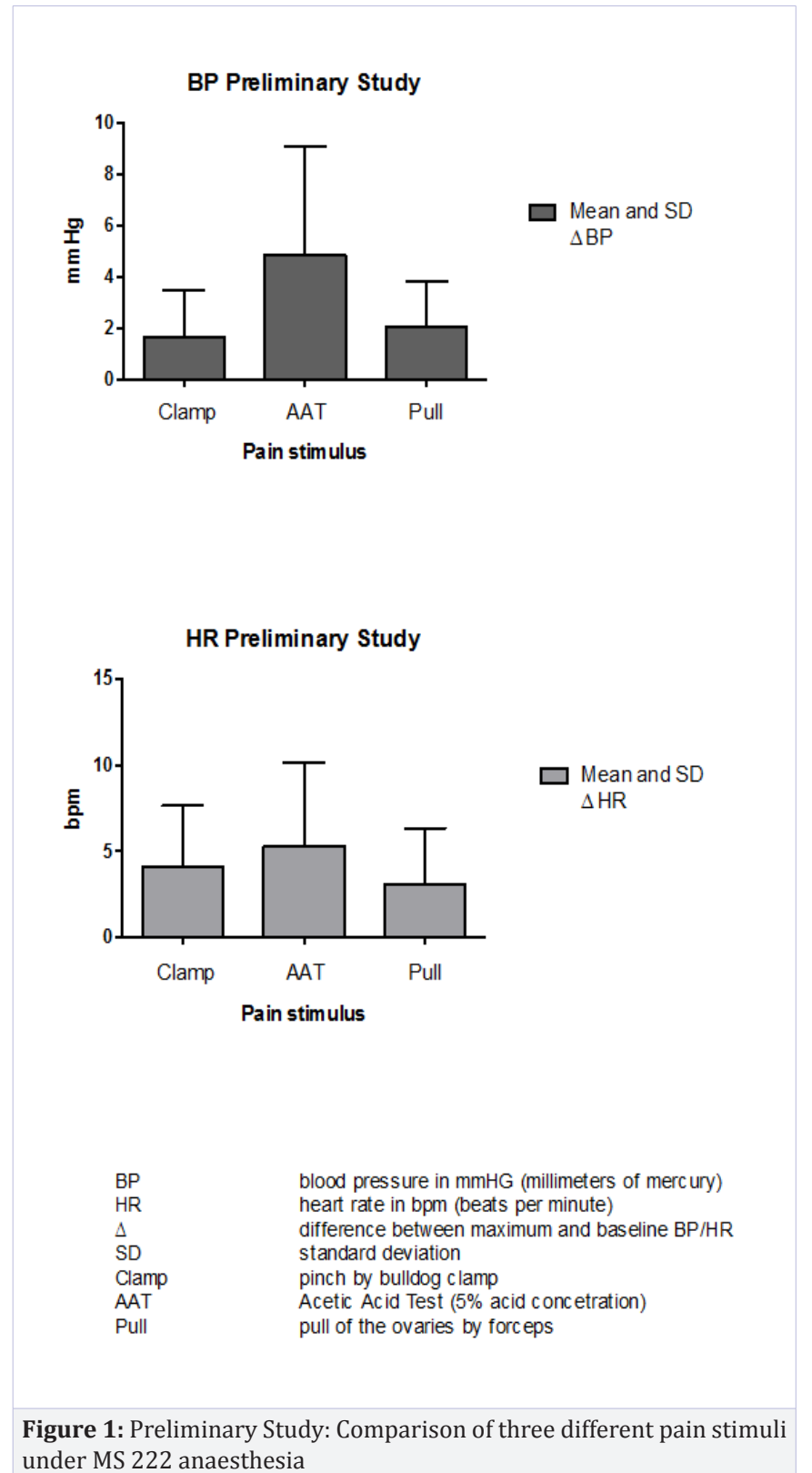
under MS 222 anaesthesia

The AAT resulted in a delta of $4.86 \pm 4.22 \mathrm{mmHg}$ for the BP and a delta of $5.30 \pm 4.81 \mathrm{bpm}$ for the HR. The increases in percent were $17.4 \%$ and $14.4 \%$, respectively.

The pull of the ovaries by forceps provoked a delta of $2.05 \pm$ $1.76 \mathrm{mmHg}$ for the BP and a delta of $3.10 \pm 3.24 \mathrm{bpm}$ for the HR, which represents increases of $7.4 \%$ and $8.2 \%$, respectively.

There with, the results of the preliminary study identified the AAT being the most reproducible nociceptive stimulus during MS222 anaesthesia. It was taken to test the analgesic potency of additional butorphanol and fentanyl in the further study design.

\section{Main Study: Analgesic addition to MS222}

Using the AAT as test pain stimulus under MS222 anaesthesia, the systolic BP and HR increased by $10.3 \%$ and 
$18.9 \%$, respectively, after the first PS prior to application of low dose fentanyl $(0.05 \mathrm{mg} / \mathrm{kg})$. The second stimulation 10 minutes after drug application (PS 2) even showed a further increase of both parameters: $21.5 \%$ for the systolic BP and $37.6 \%$ for the HR compared to baseline. However, data variance was quite high, no statistically significant differences were observed between any of the recorded time points within the low dose fentanyl group (Figure 2). Administration of the medium dose of fentanyl
$(0.25 \mathrm{mg} / \mathrm{kg})$ did not obviously influence BP or HR increase after a PS. The paired t-test showed no significant differences between the effects of the low and medium fentanyl dose (Figure 2). Application of the high fentanyl dose $(0.5 \mathrm{mg} / \mathrm{kg})$ even showed a statistically significant increase in BP and HR 20 minutes after drug application (PS 3) compared to stimulation prior to the analgesia injection.
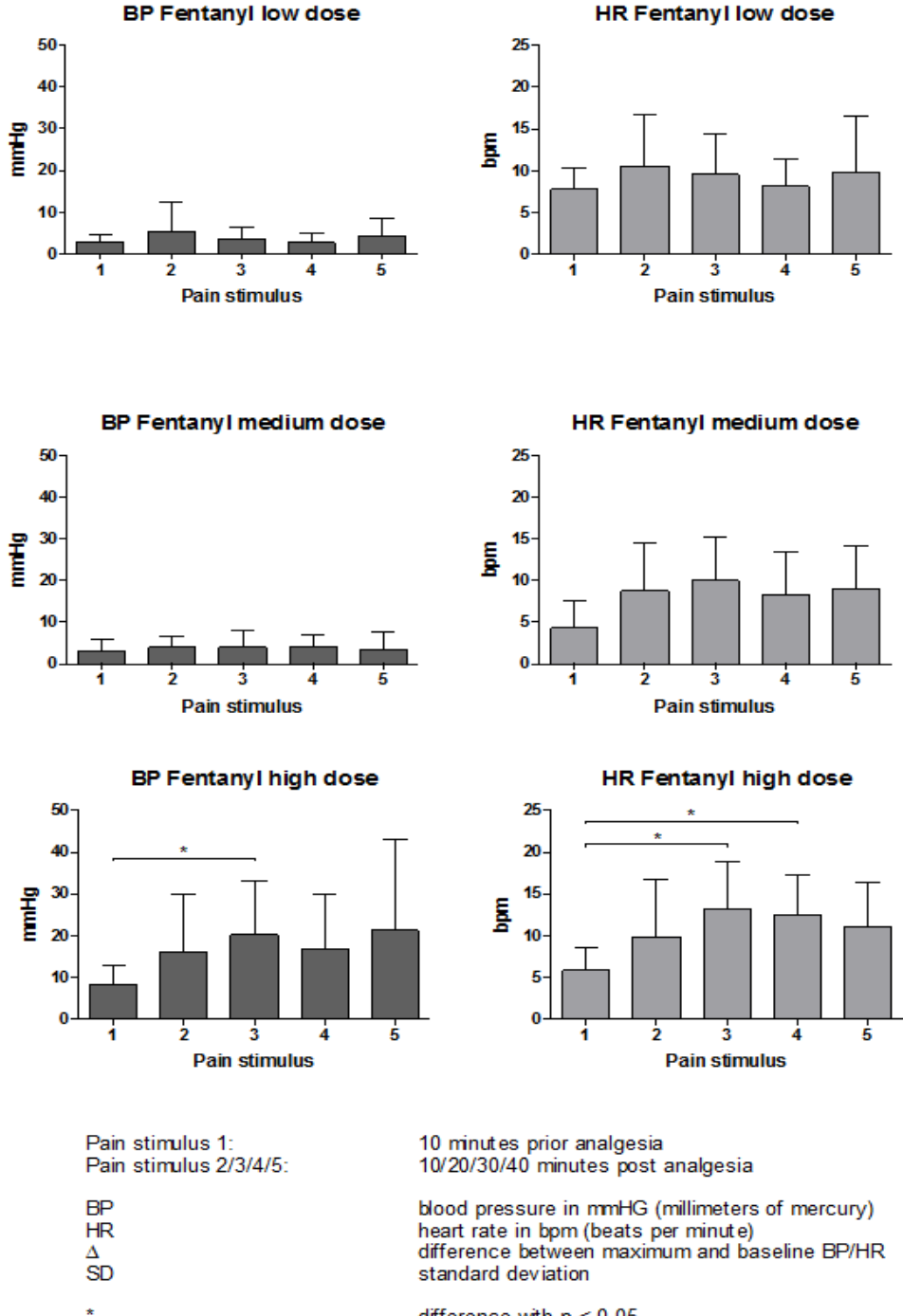

10 minutes prior analgesia 10/20/30/40 minutes post analgesia

blood pressure in $\mathrm{mmHG}$ (millimeters of mercury) heart rate in bom (beats per minute) difference between maximum and baseline $\mathrm{BP} / \mathrm{HR}$ standard deviation

difference with $p<0,05$

Figure 2: Main Study: Mean \pm SD $\Delta$ BP and $\Delta$ HR of five pain stimuli under MS222 anaesthesia and additional Fentanyl

As shown in figure 3, the drug serum level difference between the low, medium and high doses both of fentanyl $(\mathrm{p}<0.006)$ and butorphanol $(\mathrm{p}<0.000)$ could be statistically significantly confirmed. 


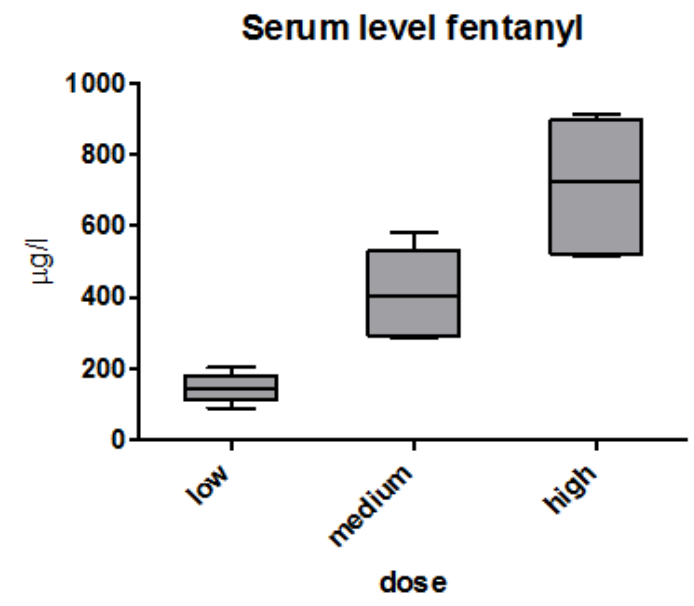

low different from medium with $p<0.006$

low different from high with $p<0.000$

medium different from high with $\mathrm{p}<0.002$

\section{Serum level butorphanol}

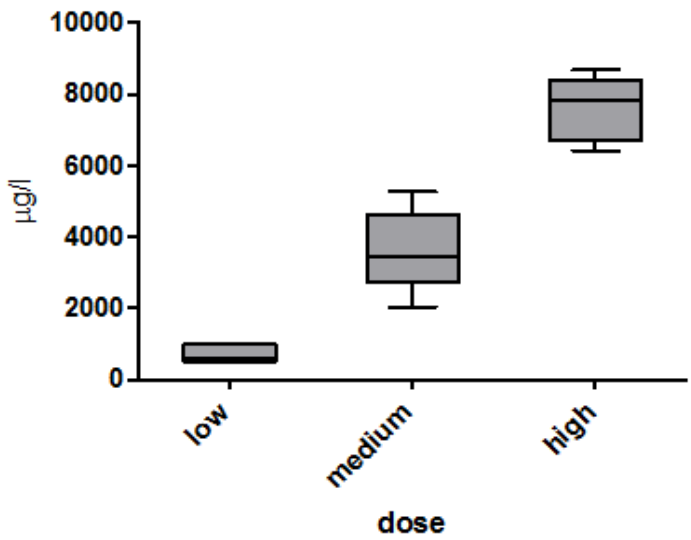

low different from medium with $p<0.000$

low different from high with $p<0.000$

medium different from high with $p<0.000$

Figure 3: Main study: Comparison of the different serum levels of Fentanyl and Butorphanol

The BP and HR results for butorphanol are shown in figure 4. The low dose of butorphanol $(0.05 \mathrm{mg} / \mathrm{kg})$ had no statistically significant effect on BP or HR. Interestingly, the application of the medium dose of butorphanol $(1.0 \mathrm{mg} / \mathrm{kg})$ affected the blood pressure significantly, it even increased from PS 3 on compared to PS 1. However, HR was not significantly changed.
Only the high dose of butorphanol $(5 \mathrm{mg} / \mathrm{kg})$ significantly decreased BP (HR not significantly) at PS 2 after drug administration compared to PS 1 before. This effect could not be reproduced though at the later time points PS 3-5 when an increase of cardiac data was observed again. 

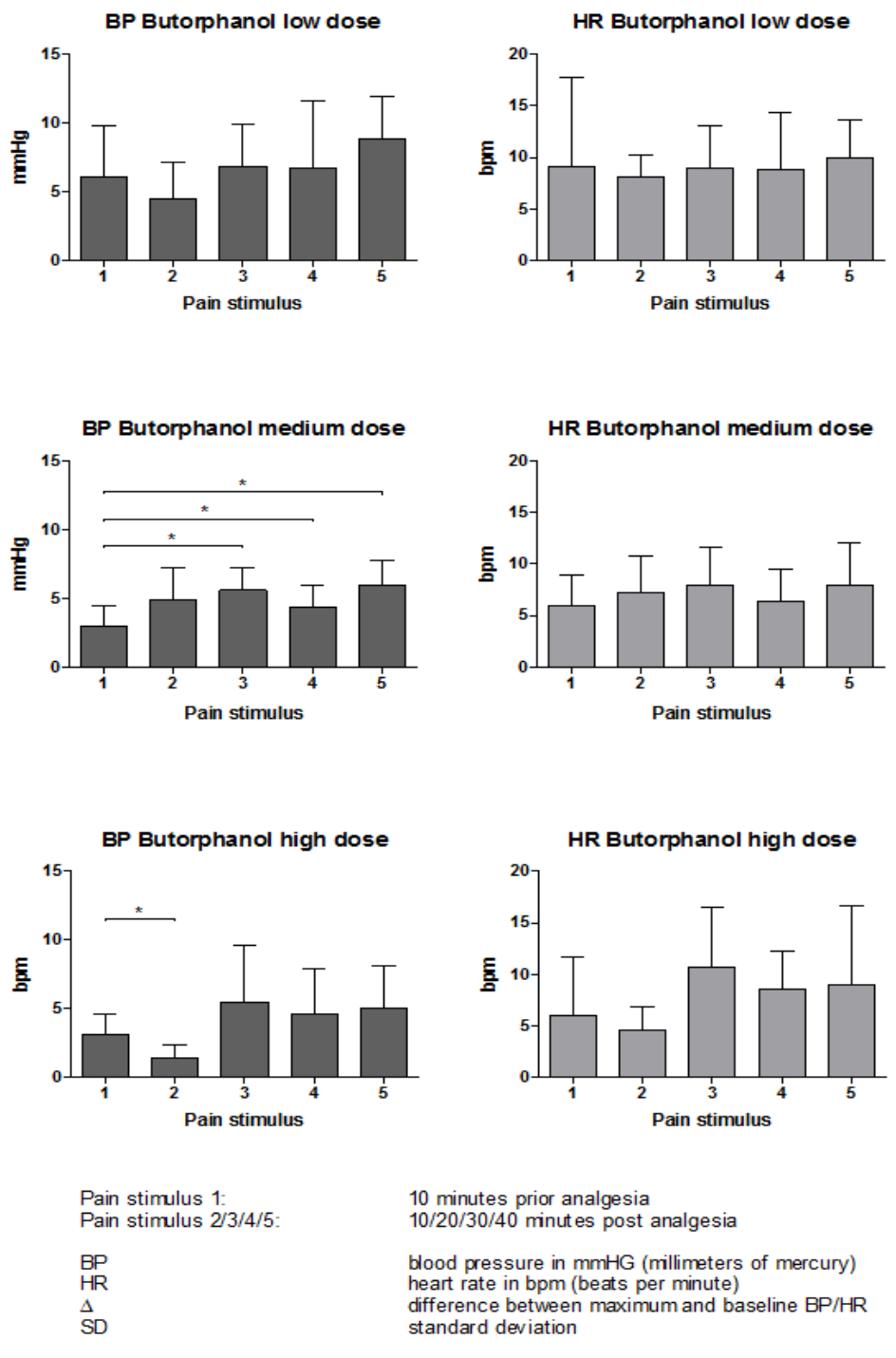

10 minutes prior analgesia 10/20/30/40 minut es post analgesia

blood pressure in mmHG (millimeters of mercury) heart rate in bpm (beats per minute) difference between maximum and baseline BP/HR standard deviation

difference with $p<0,05$

Figure 4: Main study: Mean \pm SD $\Delta$ BP and $\Delta$ HR of five pain stimuli under MS222 anaesthesia and additional Butorphanol

\section{Discussion}

As there is only poor current knowledge about intraoperative pain management in the ACF, the aim of this study was to clarify whether different Pain Stimuli (PSs) lead to nociception during anaesthesia with MS222. We used invasive systolic blood pressure and heart rate monitoring as indicators for intraoperative nociception. First, we evaluated the most sensitive and reproducible stimulus for nociception under MS222 anaesthesia before the analgesic potency of two additional opioids, fentanyl and butorphanol, was investigated at three different doses. Due to animal welfare aspects we abdicated an extra placebo control group. The preliminary study, performed with no additional analgesia, provided important information regarding that point instead. However, this was limited by the lack of potential sensitisation assessment.
In the past, several anaesthetic agents with different routes of administration have been examined in amphibians. Eugenol, benzocaine and MS222 induce general anaesthesia via immersion [18, 33 \& 44-46]. In this field, MS222 is currently the agent of choice [12, 17, 24, 47 \&48]. It is an isomer of benzocaine, is characterized by better water solubility and has an average halflife of 3.2h. [8, 18 \& 49]. Different doses of MS222 can be found in the literature: [12] $0.5 \mathrm{~g} / \mathrm{L}$ [50], $1-3 \mathrm{~g} / \mathrm{L}$ [51] or $1.5 \mathrm{~g} / \mathrm{L}$ [17]. the exact mechanism of action has not been determined, but a block of sodium currents is certainly provoked [12 \& 52]. After 30 minutes of immersion, a tolerance phase is reached in which the withdrawal, corneal and righting reflexes are lost [12]. To achieve a surgically tolerant anaesthesia though, including muscle relaxation, hypnosis and analgesia, most anaesthetic agents must be used in combination. However, some studies have asserted that this is not necessary with MS222 [18 \& 33]. 
In contrast, the results of our preliminary study showed an increase in HR and systolic BP after a painful stimulus.

Why is it important to control pain during surgery? Briefly, besides its ethical aspect, proper analgesia provides a deeper anaesthesia using lower doses. Regarding the cardiovascular system, acute pain sensation leads to a release of catecholamines, which results in an increase in HR and constriction of the peripheral vessels. These effects cause an increase in BP. In 2008, Arras demonstrated mild-to-moderate post-laparotomy pain states in laboratory mice by recording their HR and HR variability [36].

In the preliminary study, three different pain stimuli were examined in frogs under MS222. A standardised pinch by a bulldog clamp in the cloves of the forelimb is a somatic PS. The average percentage increase in BP was $6.0 \%$, and that of the HR was $10.5 \%$. Although the increase did not exceed $15 \%$, a twitch of the forelimb could be recognised at the end of the experiment, when anaesthetic level got lighter. The pulling of the ovaries by forceps is a visceral PS, and it provoked a 7.4\% increase in BP and an $8.2 \%$ increase in HR. The AAT is a somatic PS again. Currently, it is the method of choice for assessing nociception in amphibians [7, 18, 29 \& 53-56]. Briefly, the AAT is regularly performed on awake animals with an increasing series of acid concentrations to examine the nociceptive threshold of the animal. In our study, we applied the lowest evocative acid concentration (5\%) which was dropped onto the lateral area of the lower leg for $5 \mathrm{sec}$ where $61 \%$ of afferent fibres have their receptive field [29, 45, 54 \& 55]. The percentage increase in BP in the preliminary study was $17.4 \%$, and that of the HR was $14.4 \%$. Of the three different PS, the AAT was the most effective and the best to standardise. This conclusion supports the results of earlier clinical trials in the literature $[7,18,21,22,29,54 \& 55]$.

The increases in sympathetic tone after a PS demonstrate that amphibians probably have intact and active nociceptive pathways under MS222 anaesthesia resulting in intraoperative stress. This is certainly not a proof for pain perception in conscious animals. However, in 2004 Sneddon named seven indicating criteria whether an animal is capable of perceiving pain: 1) Nociceptors, 2) Brain structure, 3) Pathways to a higher brain structure, 4) Opioid receptors and substances, 5) Reduction of the nociceptive response with analgesics, 6) Avoidance learning and 7) Suspension of normal behaviour. All of these criteria refer to the class of amphibians [57]. Amphibian nociception has been recently reviewed in detail elsewhere [58]. Three different groups of primary afferent fibres have been identified in amphibians [27, 57 \& 59]. Stevens assumes that there are no major differences between the amphibian and mammalian nociceptive afferent fibres [22]. Thirty-nine percent of all primary afferent fibres become excited by the AAT, which are mainly the $A \delta$ and C fibres [29]. Nociceptive information is transmitted via ascending pathways from the spinal cord to the brain. However, the brain structures differ significantly. In regard to amphibian pain perception, the biggest difference from mammalian pain perception is the lack of cortical tissue in both the cerebrum and limbic regions. Consequently, the appreciation of pain is presumably diminished in amphibians rather than in mammals [58].

In Sneddon's numeration, point 5 is a reduced nociceptive response in conscious animals after analgesia [57]. In our study, two different opioids, fentanyl and butorphanol, were tested in three different doses each in anaesthetised Xenopus to enable the use of BP and HR to assess intraoperative stress and antinociception and therewith help to refine animal welfare due to post-operative pain and faster healing.

To ensure that the analgesic agent was totally absorbed, it was given intravenously, although the practicality of this approach might be questioned and therefore is a limitation of this study and may especially affect the time course of action of the drugs.

Fentanyl is a strongly lipophilic derivate of phenylpiperidin and has a high selectivity to the $\mu$-opioid-receptor in mammals. Its potency is 80-120 times higher than that of morphine, and its duration of effect is relatively short, ranging from 20-30 min. The side effects are strong sedation, hypothermia, bradycardia, respiratory depression and vomitus. Dosage data for amphibians in the literature range from $0.5 \mathrm{mg} / \mathrm{kg}$ s.c. to $1 \mathrm{mg} / \mathrm{kg}$ s.c. [37-39 $\&$ 60]. In rodents, Fentanyl is commonly used as an analgesic in combination with midazolam and medetomidine to induce general anaesthesia [61].

Butorphanol is a partial $\mu$-agonist/antagonist and a partial $\kappa$-agonist in mammals. The efficacy is dose-dependent, and high doses can have an antagonist effect. Its plasma half-life depends on species specific liver enzyme metabolism [60]. Data concerning the dosage vastly vary in the literature. For some authors it is the agent of choice for analgesia at a dose of $0.05-1 \mathrm{mg} / \mathrm{kg}$ i.v., p.o., i.m. or s.c. for a duration of $12 \mathrm{~h}$, while others recommend 0.2 $0.4 \mathrm{mg} / \mathrm{kg}$ i.m. or even $25 \mathrm{mg} / \mathrm{kg}$ i.p [40-42]. In comparison to rodents, butorphanol is recommended for use in mice by Cagle et al. in combination with dexmedetomidine, tiletamine, zolazepam and by Kawai et al., in combination with medetomidine and midazolam [62 \& 63]. It was shown that additional butorphanol improves the intraoperative analgesia and the efficacy of the anaesthesia.

For the refinement of animal experiments and the aim of giving proper dosage guidelines, we assayed three different dosages in accordance with the references. The results of our study have to be judged as explorative data using $n=6$, not reference-based and statistically pre-calculated. Therefore, some data show quite a wide variance. In our study, all three doses of fentanyl showed no analgesic effect. In contrast, BP and HR even increased to higher levels after painful stimulation than without analgesia, irrespective of the fentanyl dose, signifying a possible induction of hyperalgesia. In sum, the drug showed no analgesic effect but considerable side effects on the haemodynamic system of the animals. The use of fentanyl is therefore not advisable in frogs.

Butorphanol did not show any significant effect on BP and HR in the low dose group, whereas in the medium dosed group a significant BP increase could be observed compared to PS 1. In 
conclusion, neither a low dose nor a medium dose of butorphanol provided efficient analgesia in ACF. The only significant decreases in BP and HR after a noxious in put, meaning the only demonstrable analgesic effect of this study, were temporarily observed with the high butorphanol dose $10 \mathrm{~min}$ after its application at PS 2 . However, in consideration of the short duration of the analgesic effect by simultaneous cardiovascular depressive side effects, its practical benefit was not particularly evident.

In summary, we conclude that ACFs have intact and active nociceptive pathways under anaesthesia with MS222. The current anaesthetic agent of choice in amphibians induced a good unconsciousness and muscle relaxation but insufficient analgesia during the painful stimulations in our study $[12,17$ 24, 47 \& 48]. The two opioids fentanyl and butorphanol did not effectively relieve this pain. Therefore, further non-opioid analgesics (e.g., ketamine, metamizole) should be evaluated to improve intraoperative analgesia in ACFs under MS222 anaesthesia. To stay with these examples, dosages in the literature range from 20-210 mg/kg i.m., s.c., i.v. for ketamine [9]. Dosage recommendations for metamizole in amphibians are extremely rare and follow the ones for mammals: $20-100 \mathrm{mg} / \mathrm{kg}$ i.m., slowly i.v [64]. In our first preliminary trial we observed a markedly lower increase of BP and HR after a PS at a relatively low dose of $20 \mathrm{mg} / \mathrm{kg}$ ketamine given i.v. In conclusion, this might be a reference point for further studies, particularly using ketamine in the ACF for improving intraoperative analgesia with fewer side effects on the cardiovascular system.

\section{Acknowledgements}

We thank Sandra Hummel, the animal keeper, for providing good care of the animals and Dr. Johanna Brandl for her valuable input to the manuscript.

\section{Funding}

The research was gratefully supported by the Ingo- and Waltraud-Pauler-Fonds.

H. Potschka's group receives funding for the development of evidence-based severity assessment schemes from the Deutsche Forschungsgemeinschaft (DFG FOR 2591; PO 681/9-1).

\section{Declaration of conflicting interests}

The authors declare no conflicts of interest to disclose

\section{Notes}

a. Nasco, Fort Atkinson, Wisconsin, USA

b. Tierforschungszentrum, Universität Ulm, Ulm, Germany.

c. Krallenfrosch Extrudat 3mm, Provimi Kliba AG, Kaiseraugst, Swizerland.

d. Ethyl-3-aminobenzoatemethanesulfonate 98\%, Sigma-Aldrich Chemistry, St. Louis, Missouri, USA.

e. Natriumhydrogencarbonat, Merck KGaA, Darmstadt, Germany.

f. Syringe Pump, Harvard Apparatus, Holliston, Massachusetts,
USA.

g. Gazin ${ }^{\circledR}$, Lohmann \& Rauscher GmbH\&Co.KG, Rengsdorf, Germany.

h. Isotone Kochsalzlösung $0.9 \%$, B. Braun-Melsungen-AG, Melsungen, Germany.

i. Silicon tube $7 \mathrm{~mm}$, FMI Föhr-Medical-Instruments-GmbH, Seeheim, Germany.

j. Sterican ${ }^{\circledR}$ Gr.1 G20x11/2"/0.90x40mm, B. Braun-MelsungenAG, Melsungen, Germany.

k. Mikro-Tip ${ }^{\circledR}$ catheter transducers, Millar Instruments, Inc., Houston, Texas, USA.

l. PDS II 6-0 BV-1, violet monofilament absorbable suture, Johnson \& Johnson Medical GmbH, Ethicon Deutschland, Norderstedt, Germany.

m. Type "Aria", FMI Föhr-Medical-Instruments-GmbH, Seeheim Germany.

n. Essigessenz, Surig, Speyer \& Grund GmbH\&Co.KG, Mainz, Germany.

o. Fentanyl-hameln 50mikrogramm/mL Injektionslösung, Hameln pharmaceuticals GmbH, Hameln, Germany.

p. Morphasol®-4 ad. us. vet. Injektionslösung, Albrecht GmbH, Aulendorf, Germany.

q. Thiopental-Rotexmedica, $0.5 \mathrm{~g}$, Trockensubstanz, Rotexmedica $\mathrm{GmbH}$, Trittau, Germany.

r. IBM SPSS Statistics for Windows, Version 23.0. IBM Corporation, Armonk, NY, USA.

\section{References}

1. Major N and Wassersug RJ. Survey of current techniques in the care and maintenance of the African clawed frog (Xenopus laevis). Contemp Top Lab Anim Sci.1998;37(5):57-60.

2. Straka $\mathrm{H}$ and Simmers J. Xenopus laevis: an ideal experimental model for studying the developmental dynamics of neural network assembly and sensory-motor computations. Dev Neurobiol. 2012;72(4):649-663. Doi: 10.1002/dneu.20965.

3. Burggren WW and Warburton S. Amphibians as animal models for laboratory research in physiology. ILAR J. 2007;48(3):260269.

4. Hardwick LJ and Philpott A. An oncologists friend: how Xenopus contributes to cancer research. Dev Biol. 2015;408(2):180-187. Doi: 10.1016/j.ydbio.2015.02.003.

5. Beck CW and Slack JM. An amphibian with ambition: a new role for Xenopus in the 21st century. Genome Biol. 2001;2(10): reviews1029.1-reviews 1029.5

6. Green SL. Postoperative analgesics in South African clawed frogs (Xenopus laevis) after surgical harvest of oocytes. Comp Med. 2003;53(3):244-247. 
7. Coble DJ, Taylor DK and Mook DM. Analgesic effects of meloxicam, morphine sulfate, flunixin meglumine, and xylazine hydrochloride in African-clawed frogs (Xenopus laevis). J Am Assoc Lab Anim Sci. 2011;50(3):355-360.

8. Downes H. Tricaine anesthesia in Amphibia: a review. Bull ARAV. 1995;5(2):11-16.

9. Wright KM. Restraint techniques and euthanasia. In: Wright KM and Whitaker BR (eds) Amphibian medicine and captive husbandry. Malabar, FL: Krieger Publishing Company. 2001; pp.111-222.

10.IACUC. Texas Tech University Health Sciences Center and Institutional Animal Care and Use Committee (IACUC) Guidelines. Egg and oocyte harvesting from laboratory frogs (Xenopus Laevis). IACUC. 2015.

11. ARAC. Animal Research Advisory Committee (ARAC) Guidelines. Guidelines for egg and oocyte harvesting in Xenopus laevis. Animal Research Advisory Committee, 2016.

12.Kölle P, Lendl C and Henke J. Amphibien. In: Erhardt W, Henke J, Haberstroh J, et al. (eds) Anästhesie und Analgesie beim Klein- und Heimtier: mit Exoten, Labortieren, Vögeln, Reptilien, Amphibien und Fischen. Stuttgart: Schattauer Verlag, 2012; pp.870-890.

13. Wayson KA, Downes H, Lynn RK and Gerber N. Studies on the comparative pharmacology and selective toxicity of tricaine methanesulfonate: metabolism as a basis of the selective toxicity in poikilotherms. J Pharmacol Exp Ther. 1976;198(3):695-708.

14. Williams CJA, Alstrup AKO, Bertelsen MF, Jensen HM, Leite CAC and WangT. When local anesthesia becomes universal: Pronounced systemic effects of subcutaneous lidocaine in bullfrogs (Lithobates catesbeianus). Comp Biochem Physiol A Mol Integr Physiol. 2017;209: 41-46. Doi: 10.1016/j.cbpa.2017.03.019.

15.Lalonde-Robert V, Desgent S, Duss S and Vachon P. Electroencephalographic and physiologic changes after tricaine methanesulfonate immersion of African clawed frogs (Xenopus laevis). J Am Assoc Lab Anim Sci. 2012;51(5):622-627.

16. Paduano M, Colafrancesco KC, Wong SA, Caldwell MS and Papp MG. The response of gray tree frogs to anesthesia by tricaine methanesulfonate (TMS or MS-222). ISRN Zoolology. 2013;635704:9.

17. Cakir Y and Strauch SM. Tricaine (MS-222) is a safe anesthetic compound compared to benzocaine and pentobarbital to induce anesthesia in leopard frogs (Rana pipiens). Pharmacol Rep. 2005;57(4):467-474.

18. Lalonde-Robert V, Beaudry F and Vachon P. Pharmacologic parameters of MS222 and physiologic changes in frogs (Xenopus laevis) after immersion at anesthetic doses. J Am Assoc Lab Anim Sci. 2012;51(4):464-468.

19. Hernández SE, Sernia C and Bradley AJ. The effect of three anaesthetic protocols on the stress response in cane toads (Rhinella marina). Vet Anaesth Analg. 2012;39(6):584-590. Doi: 10.1111/j.14672995.2012.00753.x.
20. Koustubhan P, Kaplan DL and Levin M. Humane anesthesia and pain management in amphibian limb surgery of Rana pipiens. Cold Spring Harb Protoc. 2013;2013(2):149-155. Doi: 10.1101/pdb.prot071977.

21. Stevens CW. Alternatives to the use of mammals for pain research. Life Sciences. 1992;50(13):901-912.

22.Stevens CW. Analgesia in amphibians: preclinical studies and clinical applications. Vet Clin North Am Exot Anim Pract. 2011; 14(1):33-44. Doi: 10.1016/j.cvex.2010.09.007

23.Kaplan HM. Anesthesia in amphibians and reptiles. Fed Proc. 1969;28(4):1541-1546.

24.Guénette SA, Giroux MC and Vachon P. Pain perception and anaesthesia in research frogs. Exp Anim. 2013;62(2):87-92.

25. Fox H and Whitear M. Observations of Merkel cells in amphibians. Biol Cell. 1978;32(2):223-232.

26. Habgood JS. Sensitization of sensory receptors in the frog's skin. J Physiol. 1950;111(1-2):195-213.

27. Spray DC. Pain and temperature receptors of Anurans. In: Llinás R and Precht W (eds) Frog neurobiology, a handbook. Berlin: Springer. 1976;pp.607-628.

28.Yamashita Y and Ogawa H. Slowly adapting cutaneous mechanoreceptor afferent units associated with Merkel cells and effects of direct currents. Somatosens Mot Res. 1991;8(1):87-95.

29. Hamamoto DT and Simone DA. Characterization of cutaneous primary afferent fibers excited by acetic acid in a model of nociception in frogs. J Neurophysiol. 2003;90(2):566-577. DOI: 10.1152/ jn.00324.2003

30. Sneddon LU. Comparative Physiology of Nociception and Pain. Physiology. 2018;33(1):63-73. Doi: 10.1152/physiol.00022.2017.

31. Vesselkin NP, Agayan AL, Nomokonova LM. A study of thalamotelencephalic afferent systems in frogs. Brain Behav Evol. 1971; 4(4):295-306. DOI: 10.1159/000125439.

32.Erhardt W. Definition, Aufgaben und Bedeutung der tierärztlichen Anästhesie. In: Erhardt W, Henke J, Haberstroh J, C. Baumgartner and S.Tacke. Anästhesie und Analgesie beim Klein- und Heimtier: mit Exoten, Labortieren, Vögeln, Reptilien, Amphibien und Fischen. Stuttgart: Schattauer Verlag, 2012, pp.7-9.

33. Ramlochansingh C, Branoner F, Chagnaud BP and Straka H. Efficacy of tricaine methanesulfonate (MS-222) as an anesthetic agent for blocking sensory-motor responses in Xenopus laevis tadpoles. PLoS One. 2014;9(7):e101606.

34.von Dincklage F, Correll C, Schneider MH, Rehberg B andBaars JH. Utility of Nociceptive Flexion Reflex Threshold, Bispectral Index, Composite Variability Index and Noxious Stimulation Response Index as measures for nociception during general anaesthesia. Anaesthesia. 2012;67(8):899-905. Doi: 10.1111/j.13652044.2012.07187.x. 
35. Richter T. Evaluation of metamizole vs. fentanyl as intraoperative analgesia - a clinical study in dogs. München, Germany: LudwigMaximilians-Universität, 2007.

36.Arras M, Rettich A, Cinelli P, Kasermann HP and Burki K. Assessment of post-laparotomy pain in laboratory mice by telemetric recording of heart rate and heart rate variability. BMC Vet Res. 2007;3:16. doi: 10.1186/1746-6148-3-16.

37. Machin KL. Amphibian pain and analgesia. J Zoo Wildl Med. 1999;30(1):2-10.

38. Machin KL. Fish, amphibian, and reptile analgesia. Vet Clin North Am Exot Anim Pract. 2001;4(1):19-33.

39. Chinnadurai SK and Kane LP. Advances in Amphibian clinical therapeutics. J Exot Pet Med. 2014;23(1):50-55.

40.Ströse D and Kempf H. Dosierungsvorschläge bei Amphibien. In: Ströse D, Schütz S, Schütz S, et al. (eds) Dosierungsvorschläge für Arzneimittel bei Vögeln, Reptilien, Amphibien und Fischen. Stuttgart: Schattauer Verlag, 2013, pp.228-229.

41. Schuhmacher J. Anesthesia and immobilization of specific species. Reptiles and amphibians. In: Thurmon JC, Tranquilli WJ and Benson GJ (eds) Lumn and Jones' veterinary anesthesia. Baltimore: Williams and Wilkins, 1996, pp.670-685.

42.Terril-Robb L, Suckow M and Grigdesby C. Evaluation of the analgesic effects of butorphanol tartrate, xylazine hydrochloride, and flunixin meglumine in leopard frogs (Rana pipiens). Contemp Top Lab Anim Sci. 1996;35(3):54-56.

43. Torreilles SL, McClure DE and Green SL. Evaluation and refinement of euthanasia methods for Xenopus laevis. J Am Assoc Lab Anim Sci. 2009;48(5):512-516.

44.Guénette SA, Hélie P, Beaudry F andVachon P. Eugenol for anesthesia of African clawed frogs (Xenopus laevis). Vet Anaesth Analg. 2007;34(3):164-170.

45. Goulet F, Hélie P and Vachon P. Eugenol anesthesia in African clawed frogs (Xenopus laevis) of different body weights. J Am Assoc Lab Anim Sci. 2010;49(4):460-463.

46.Zahl IH, Samuelsen O and Kiessling A. Anaesthesia of farmed fish: implications for welfare. Fish Physiol Biochem.2012;38(1):201-218. Doi:10.1007/s10695-011-9565-1.

47. Gentz EJ. Medicine and surgery of amphibians. ILAR J. 2007;48(3):255-259.

48.Beckman M. Therapeutic review: tricaine methanesulfonate. J Exot Pet Med. 2016;25(3):261-263.

49. Longley LA. Amphibian anesthesia. In: Longley LA (ed) Anaesthesia of exotic pets. Edinburgh: Saunders Elsevier. 2008;pp.245-252.

50. Chai $\mathrm{N}$ and de Luze A. Medicine and surgery in amphibians. In: Proceedings of the 7th Scientific Meeting of the European Association of Zoo and Wildlife Veterinarians, Leipzig, Germany. 2008;pp.185-
188.

51. Bonath K. Narkose der Reptilien, Amphibien und Fische. Berlin: Paul Parey. 1977.

52.Frazier DT and Narahashi T. Tricaine (MS-222): effects on ionic conductances of squid axon membranes. Eur J Pharmacol. 1975;33(2):313-317.

53.Stevens CW. Opioid antinociception in amphibians. Brain Res Bull. 1988;21(6):959-962.

54.Pezalla PD. Morphine-induced analgesia and explosive motor behavior in an amphibian. Brain Res. 1983;273:297-305.

55. Hamamoto DT, Forkey MW, Davis WL, Kajander KC and Simone DA. The role of $\mathrm{pH}$ and osmolarity in evoking the acetic acid-induced wiping response in a model of nociception in frogs. Brain Res. 2000;862(1-2):217-229.

56.Vachon P. Hargreaves does not evaluate nociception following a surgical laparotomy in Xenopus leavis frogs. Res Vet Sci. 2014;97(2):470-473. Doi: 10.1016/j.rvsc.2014.06.009.

57. Sneddon LU. Evolution of nociception in vertebrates: comparative analysis of lower vertebrates. Brain Res Brain Res Rev. 2004;46(2):123-130. DOi:10.1016/j.brainresrev.2004.07.007.

58.Stevens CW. Opioid research in amphibians: an alternative pain model yielding insights on the evolution of opioid receptors. Brain Res Brain Res Rev. 2004;46(2):204-215. Doi: 10.1016/j.brainresrev.2004.07.003.

59. Stevens CW and Willenbring S. Pain sensation and analgesia in amphibians and reptiles. In: Ackerman L (ed) The biology, husbandry and health care of reptiles and Amphibians. Neptune City: TFH Publications. 1997; pp.309-324.

60. Ammer $\mathrm{H}$ and Potschka H. Pharmakologie des zentralen Nervensystems (ZNS). In: Löscher W and Richter A (eds) Lehrbuch der Pharmakologie und Toxikologie für die Veterinärmedizin. Stuttgart: Enke Verlag. 2016;pp.151-153.

61. Henke J, Erhardt W. Nager. In: Erhardt W, Henke J, Haberstroh J, et al. (eds) Anästhesie und Analgesie beim Klein- und Heimtier: mit Exoten, Labortieren, Vögeln, Reptilien, Amphibien und Fischen. Stuttgart: Schattauer Verlag. 2012;pp.703-725.

62.Cagle LA, Franzi LM, Epstein SE, Kass PH, Last JA and Kenyon NJ. Injectable anesthesia for mice: combined effects of dexmedetomidine, tiletamine-zolazepam, and butorphanol. Anesthesiol Res Practice. 2017;2017: 7 .

63. Kawai S, Takagi Y, Kaneko S and Kurosawa T. Effect of three types of mixed anesthetic agents alternate to ketamine in mice. Exp Anim. 2011;60(5):481-487.

64.Henke J, Tacke S, Erhardt W. Analgesie. In: Erhardt W, Henke J, Haberstroh J, et al. (eds) Anästhesie und Analgesie beim Klein- und Heimtier: mit Exoten, Labortieren, Vögeln, Reptilien, Amphibien und Fischen. Stuttgart: Schattauer Verlag. 2012; pp.383-434. 